\title{
El Chiostro dello scalzo, joya oculta de la Florencia del cinquecento
}

The Chiostro dello scalzo, hidden jewel of the Florence of the cinquecento

José Manuel Leiva Aldea

Graduado en Historia del Arte, Universidad de Málaga, España (joseleivaaldea@gmail.com)

Recibido el 5 de junio de 2017; revisado el 20 de julio de 2017; aceptado el 17 de agosto de 2017; publicado el 1 de septiembre de 2017

RESUMEN: Este artículo aborda el trabajo realizado por Andrea del Sarto y su ayudante Franciabigio para el claustro de la Compagnia dello Scalzo, creando uno de los ciclos pictóricos más interesantes de Florencia. En él se narra la vida de san Juan Bautista, patrón de la hermandad y de la ciudad, a través de una serie de frescos realizados con la técnica de grisalla.

PALABRAS CLAVE: Florencia, Andrea del Sarto, Renacimiento.

\section{RIASSUNTO:}

Questo articolo affronta il lavoro fatto per Andrea del Sarto e il suo collaboratore Franciabigio per il Chiostro della Compagnia dello Scalzo, creando una delle serie pittoriche di più rilevanza a Firenze. In questo ciclo si racconta la vita di san Giovanni Battista, santo protettore della confraternita e della città, con una serie di affreschi realizzati con la tecnica della grisaglia

PAROLE CHIAVE: Firenze, Andrea del Sarto, Rinascimento 
Y cada día siendo conocido de más personas, le fueron encargados muchos cuadros y cosas de importancia Giorgio Vasari

\section{Introducción}

Cuando el turista del s. XXI viaja a Florencia, sabe de la existencia de una serie de hitos históricoartísticos de visita «obligada», tales como el Duomo, el Ponte Vecchio, la Piazza della Signoria o la Galleria degli Uffizi, entre otros. Pero en la capital toscana, hay otros puntos de interés que suelen pasar desapercibidos para el visitante. Uno de ellos es el Chiostro dello Scalzo, un pequeño claustro a escasos metros de la céntrica Piazza San Marco. Por su apariencia externa quizás no llame la atención del viandante, pero una vez en su interior descubriremos uno de los conjuntos pictóricos más interesantes de la Florencia del Cinquecento. Fue realizado casi en su totalidad por Andrea del Sarto, considerado como «el pintor sin errores».

A día de hoy, las publicaciones principales en torno a este conjunto se reparten entre autores anglosajones (Shearman, 1960), italianos (Pisani, 1995 y 2004) y alemanes (Hirdt, 2006), entre otros. Para este artículo nos hemos ayudado de una tesis doctoral publicada en 2006 por la Universidad Estatal de Pensilvania (Dow, 2006), en la que se hace un estudio íntegro de la Compagnia di San Giovanni Battista dello Scalzo, en la que además del claustro, se analiza todo el conjunto y su organización.

\section{La Compagnia dello Scalzo}

Las fuentes del s. XV nos informan que a finales del s. XIV se fundó la Compagnia di San Giovanni Battista, hermandad de disciplinantes que contaba con san Juan Bautista (patrón de Florencia), como advocación principal (Dow, 2006: 22), en un contexto en el que surgían e iban creciendo numerosas hermandades en Florencia fruto del auge económico y cultural que atravesaba la capital toscana. Éstos efectuaban procesiones en las que algunos hermanos se flagelaban, mientras que otros, descalzos (de ahí el sobrenombre de dello Scalzo, «de los descalzos»), portaban cruces (Dow, 2006: 55-56). Este tipo de hermandades al igual que las españolas, tenía entre sus cometidos asegurar un funeral digno y el enterramiento de los confratelli o hermanos que pagaban sus cuotas, algo que sigue vigente hoy día entre numerosas cofradías de la geografía andaluza, además de ofrecer asistencia espiritual y ayudas en tiempos de carestía (solo para los hermanos, ya que estas organizaciones solían ser muy exclusivas 
y solo prestaban sus servicios a los confratelli). Se sabe que algunos artistas eran eximidos de las tasas mediante la entrega de esculturas, que configuraban un programa iconográfico sobre los apóstoles que no se ha conservado (Dow, 2006: 7).

Poco a poco, la cofradía fue consiguiendo un mayor número de hermanos, pudiéndose permitir la construcción de un oratorio considerable en el que se fueron incluyendo obras de arte y reliquias destacadas, además de otras estancias para las reuniones que se celebraban. No obstante, en 1785, fruto de las reformas de la Casa de Lorena, se derruyó gran parte del conjunto arquitectónico, salvo el claustro, que pasó a formar parte de la Accademia di Belle Arti (Dow, 2006: 162).

\section{El Chiostro dello Scalzo}

Aunque el oratorio se destruye en el s. XVIII, un pequeño espacio ha sobrevivido al paso del tiempo y llega a nosotros en unas condiciones de conservación bastante aceptables. La entrada al edificio, en Via Cavour, 69, es muy sobria, aunque tenemos que destacar el luneto cerámico, probablemente realizado por Giovanni o Andrea della Robbia, dos de los ceramistas más activos del taller Della Robbia durante el s. XVI. El profesor Paatz, comparándola con representaciones de otras iglesias, llega a la conclusión de que esta obra, realizada durante las dos primeras décadas de la centuria, corresponde a la mano del primero, con ayuda de los miembros del taller para las figuras de los flagelantes ${ }^{1}[1]$.

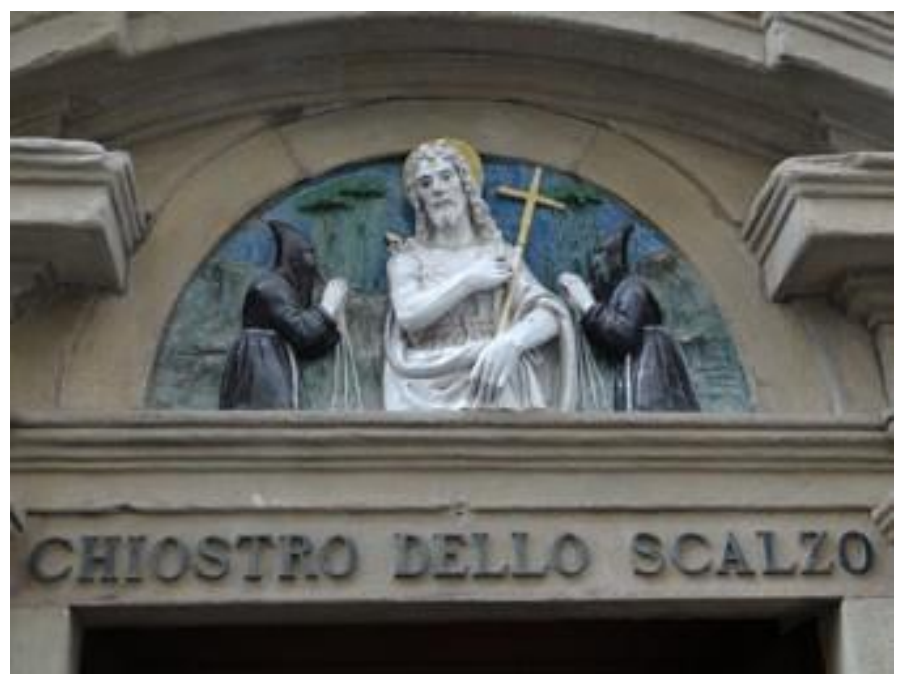

[Fig. 1] La proyección externa de la hermandad se materializa con este luneto que decora la entrada del edificio (Archivo del autor).

\footnotetext{
${ }^{1}$ Ministero per i Beni e le Attività Culturali. Recuperado de http://www.culturaitalia.it/opencms/museid/viewItem.jsp?language=it\&id=oai\%3Aculturaitalia.it\%3Amuseiditaliawork 63653 (Consultado: 5/6/2017)
} 
En este luneto se inserta una representación de san Juan Bautista, titular de la hermandad, flanqueado por dos hermanos flagelantes, que cubren sus cabezas con caperuzas a la vez que dirigen piadosamente la mirada hacia su santo protector. Dicha escena se contextualiza dentro de un entorno rural.

El edificio se separa del exterior con un pequeño vestíbulo que sirve como recepción para los visitantes hoy día. Este espacio, junto al claustro, se conciben inicialmente como «atrio», remarcando una separación tanto física como espiritual entre la zona sagrada de la hermandad, su oratorio y la profana de la calle, un témenos cristianizado que podría evocar el atrio de las antiguas iglesias paleocristianas. Según Dow, esta diferenciación simbólica de los espacios nos indica cómo el Chiostro dello Scalzo era un espacio único y exclusivo para los confratelli (Dow, 2006: 98).

Sobre los orígenes del claustro tenemos pocos datos en cuanto a autoría, siendo modificado en 1722 por el arquitecto Pietro Giovanozzi, sin intervenciones posteriores salvo la restauración efectuada en 1995 con motivo de la apertura al público. Tiene forma rectangular, siguiendo la elegancia y armonía propias de la arquitectura florentina, con reminiscencias de sus palacios. En él se insertan elementos característicos de la misma como el dado brunelleschiano sobre los capiteles. En los 2 muros cortos se disponen 2 puertas (cegada en la que daba paso al llamado ricetto dello scrivano), con una inscripción latina sobre ellas. En el muro sur, el del vestíbulo, coronado por un busto de Andrea del Sarto (Alessandro Domenico Geri, 1724), se dice LAUDATE DOMINUM IN ATRIO SANCTO EIUS («Alabad al Señor en su atrio santo»), mientras que en el norte otra se lee INTROIBO IN DOMUM TUA («Entraré en tu casa»), preparando espiritualmente a los hermanos antes de entrar en el oratorio de su cofradía [2].

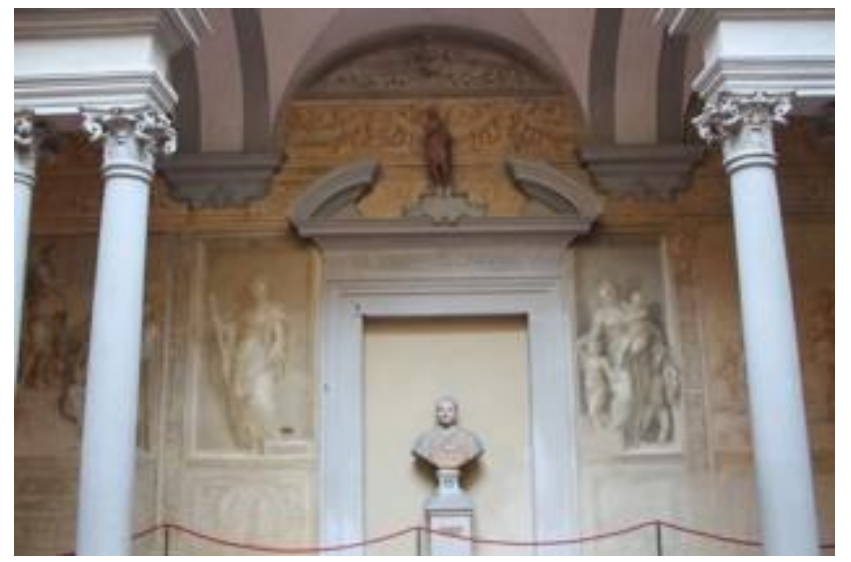

[Fig. 2] Pared sur, con representaciones de la Justicia y la Caridad. Podemos apreciar también el busto de San Antonino de Florencia, dominico y obispo de la ciudad en el s. XV, bajo una estatua en terracota de San Juan Bautista (Archivo del autor) 
El principal atractivo de este espacio son los frescos en grisalla realizados por Andrea del Sarto y su ayudante Franciabigio entre 1509-1526, con un total de 16 imágenes (12 escenas de la vida de san Juan Bautista y 4 representaciones de las virtudes, concebidas éstas últimas como si fueran esculturas). A esto se une una serie de arquitecturas fingidas (columnas, frisos, grutescos...) que enmarcan las distintas representaciones. Cada una de las escenas está «sustentada» por unos basamentos también pintados por Del Sarto, aunque algunos de ellos se han borrado casi en su totalidad. Mejor se han conservado las 4 basas sobre las que se sitúan las virtudes:

- $\quad \boldsymbol{F e}$ (Andrea del Sarto, ca. 1523)

- Esperanza (Andrea del Sarto, ca. 1523)

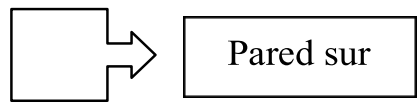

- Justicia (Andrea del Sarto, ca. 1515)

- Caridad (Andrea del Sarto, ca. 1513-1514)
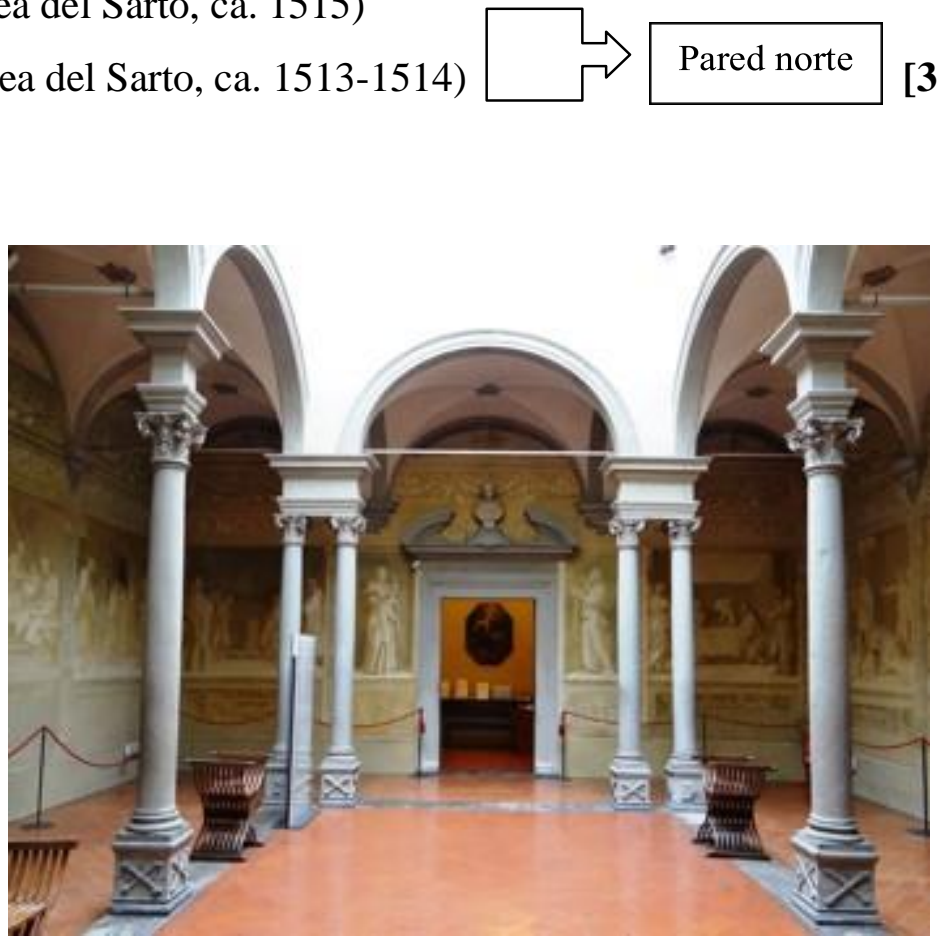

[Fig. 3] Vista general del Chiostro, con el vestíbulo al fondo (Archivo Autor)

En los basamentos de la Fe, la Esperanza y la Justicia se incluyen unos tondos con diversas representaciones, habiéndose borrado el de la Caridad. En el de la Fe aparece san Juan elEvangelista con un cáliz del que sale una serpiente, pasaje de la Leyenda Dorada en el que san Juan acepta beber de un cáliz con veneno para demostrar el poder de Dios (De la Vorágine, 2008: 40-42). La Esperanza se configura con dos obispos santos en su tondo, mientras que la Justicia también ilustra dos figuras humanas, pero difícilmente identificables. 


\section{Ciclo del Bautista (1509-1526)}

Las 12 escenas con la vida del primo de Jesucristo están dispuestas en orden cronológico (se suceden en sentido antihorario), aunque la intervención de los artistas no se corresponde con el orden de las mismas, ya que las primeras en realizarse fueron las centrales. 10 de los 12 frescos son obra de Andrea del Sarto, cofrade de la hermandad, salvo dos escenas realizada por Franciabigio, durante los dos años que pasó el primero en la corte del rey Francisco I de Francia.

A continuación, incluimos el elenco de cada uno de los frescos que narran la vida del Bautista, según la datación oficial que proporcionan las hojas informativas del Chiostro dello Scalzo:

1. Anunciación del nacimiento a Zacarías (Andrea del Sarto, 1523)

2. La Visitación (Andrea del Sarto, 1524)

3. Nacimiento de san Juan Bautista (Andrea del Sarto, 1526)

4. Bendición de san Juan Bautista Niño (Franciabigio, 1519)

5. Encuentro de Jesús y san Juanito en el desierto (Franciabigio, 1518)

6. Bautismo de Cristo (Andrea del Sarto, ca. 1509-1510) $\rightarrow$ Primera obra del realizada

7. Predicación ante las multitudes (Andrea del Sarto, 1515)

8. Bautismo de las multitudes (Andrea del Sarto, 1517)

9. Captura del Bautista (Andrea del Sarto, 1517)

10. Danza de Salomé (Andrea del Sarto, 1522)

11. La Degollación del Bautista (Andrea del Sarto, 1523)

12. Presentación de la cabeza del Bautista (Andrea del Sarto, 1523)

En estos frescos, y como es habitual en su obra, Del Sarto recurre a un eclecticismo que toma algunas de las características principales de los artistas más destacados de su momento, como la grazia de Rafael, el sfumato leonardesco o la fuerza física de Miguel Ángel. De este último cabría destacar algunos de los cuerpos masculinos, como los del Bautista o Cristo, presentados por Del Sarto en la plenitud de su belleza física. La obra de Franciabigio, aun siendo deudora de la de su maestro, es algo más intimista, y menos personal que la de Andrea (Polo Museale Fiorentino, 2009).

De las doce escenas hemos querido destacar dos, Bautismo de Cristo (ca. 1509-1510) y la Predicación del Bautista (1515). 
«Entonces, Jesús vino de Galilea a Juan al Jordán, para ser bautizado por él» (Mateo, 1998: 1422). Para el Bautismo de Cristo, primera intervención de Del Sarto en el claustro, creemos que el pintor pudo tomar como fuente de inspiración para la composición la obra homónima que había realizado Verrocchio algunos años antes (ca. 1475-1478). Ambas escenas se construyen de igual manera, con Cristo en el centro, sobre las aguas del río Jordán, mientras que san Juan Bautista, a nuestra derecha, derrama agua sobre su cabeza. En el fresco, el santo se sitúa sobre una roca, mientras que en la obra de Verrocchio también está en el cauce del río. A nuestra izquierda, dos ángeles arrodillados presencian la escena, con rostros más «humanos» que los que incluyera Leonardo da Vinci en la obra de Verrocchio [4].

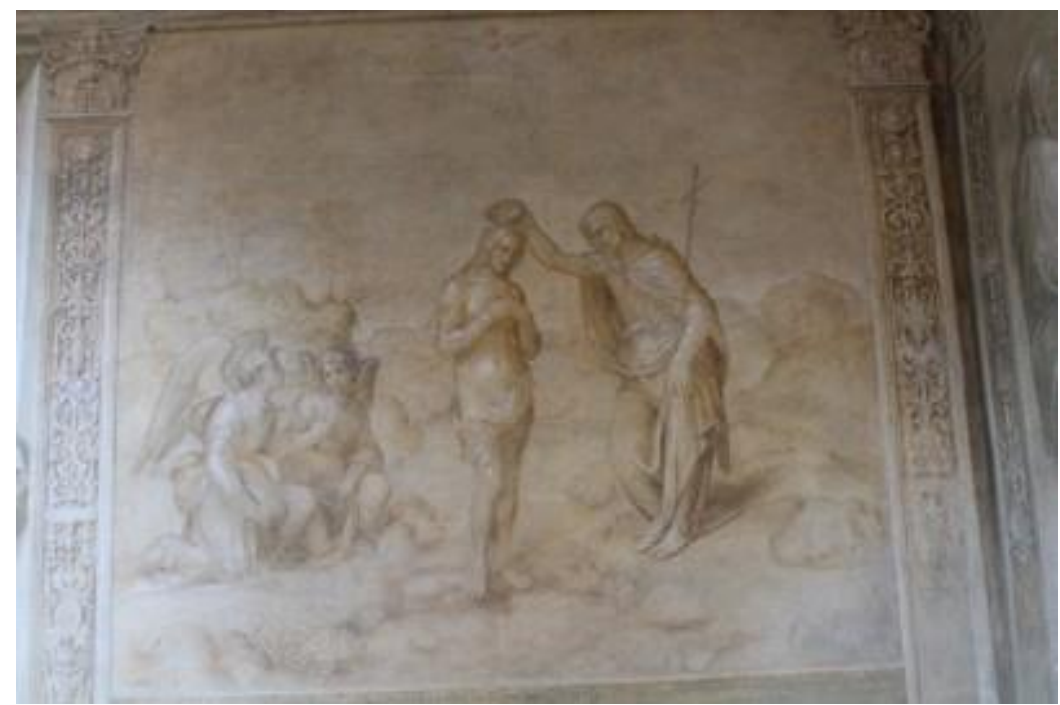

[Fig. 4] Bautismo de Cristo (Andrea del Sarto, ca. 1509-1510) (Fuente: Archivo Autor)

Según el Evangelio de san Mateo, Juan fue a predicar al desierto de Judea, anunciando la inminente llegada del Reino de los Cielos, a la vez que advertía a fariseos y saduceos por los pecados que éstos cometían (san Mateo, 1998: 1421-1422). Nuevamente, Del Sarto parece tomar como referencia otros ejemplos pictóricos conocidos dentro del ámbito artístico de Florencia. En este caso pudo inspirarse en la Predicación del Bautista de Domenico Ghirlandaio (ca. 1485-1490), incluida dentro del programa iconográfico de la Cappella Tornabuoni (Basílica de Santa María Novella). En la obra de nuestro pintor, la adaptación al marco arquitectónico hace que sea algo más reducida que la de la Cappella Tornabuoni, aunque mantiene las líneas generales de ésta: san Juan Bautista, vestido con las pieles de camello, actúa como eje central de la composición, predicando a la multitud de hombres y mujeres que lo rodea. A nuestra izquierda, vemos a Cristo, que aparece bajando por lo que parece ser el camino de una montaña, al igual que en la obra de Ghirlandaio, ya que, según las concordancias 
bíblicas, el bautismo se produjo después de estas predicaciones. Una diferencia respecto al fresco de Santa Maria Novella es que en la obra de Del Sarto todo el entorno es rural, mientras que en la de Domenico podemos divisar una ciudad renacentista al fondo de la escena [5].

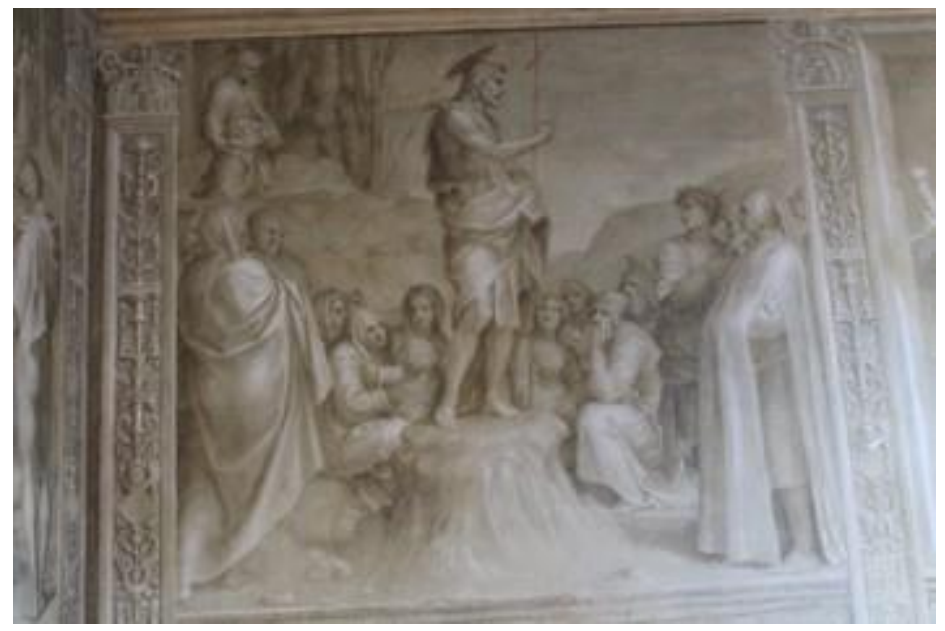

[Fig. 5] Predicación de san Juan Bautista (Andrea del Sarto, 1515) (Fuente: Archivo Autor)

\section{Conclusiones}

Mientras que Florencia fue el principal centro de creación artística en Italia durante el Quattrocento, Roma y Venecia recogerán el testigo durante el Cinquecento con el Alto Renacimiento y Manierismo. No obstante, la excelencia artística siguió vigente en la capital toscana durante el s. XVI con una generación de pintores notables. Entre ellos, además del citado del Sarto, destacan otros como Rosso Fiorentino, Pontormo, Fra Bartolomeo o Bronzino, principales referentes del Manierismo florentino.

Con la colaboración de Andrea del Sarto en la Compagnia dello Scalzo, se anticipan una serie de principios que, tras finalización del Concilio de Trento y durante el s. XVII se difundieron entre las diversas creaciones plásticas de la Iglesia Católica. Si bien la exaltación de los valores de la doctrina católica como las virtudes y las vidas ejemplares de los santos fue una de las constantes tras la Reforma Católica (preferimos esta terminología a la de Contrarreforma, ya que se trata más de una reforma interna que una respuesta contra los protestantes), esta actitud, que se consideraría como barroca, se manifiesta varias décadas antes del denominado Barroco histórico.

Por otro lado, decíamos que algunos artistas eran eximidos de las cuotas requeridas para pertenecer a las hermandades a cambio del pago a través de obras de arte. Esta actitud nos pone de 
manifiesto la existencia de vías indirectas de mecenazgo artístico alternativas al encargo tradicional. A fin de cuentas, consideramos que aun sin la primacía que gozó durante el s. XV, la pintura florentina del s. XVI cuenta con ejemplos relevantes y de primer nivel como el ciclo de frescos del Chiostro dello Scalzo.

\section{Recursos Bibliográficos}

DE LA VORÁGINE, Santiago (2008). La leyenda dorada. Alianza Editorial: Madrid.

DOW, Douglas, N (2006). Confraternal Piety and Corporate Patronage: A reconstruction of the art and oratory of the Company of San Giovanni Battista dello Scalzo, Florence. The Pennsylvania State University: Pensilvania.

HIRDT, Willi (2006). Barfuß zum lieben Gott: der Freskenzyklus Andrea del Sarto sim Florentiner Chiostro dello Scalzo, Francke: Tubinga.

MATEO, San (1998). Biblia de Jerusalén. Editorial Desclée de Brouwer: Bilbao.

PISANI, Proto (1995). Il Chiostro dello Scalzo. Giorgi \& Gambi Editori: Florencia.

PISANI, Proto (2004). Il Chiostro dello Scalzo a Firenze. Studio e scuola di pittura. Sillabae Editore: Florencia.

POLO MUSEALE FIORENTINO (2009). El Claustro del Scalzo [Folleto informativo]. Sezione Didattica del Polo Museale Fiorentino: Florencia.

SHEARMAN, John K. G. (1960), 'The Chiostro dello Scalzo', Mitteilungen des Kunsthistoriches Institutes in Florenz, n⿳3 y 4, pp. 207-220.

VASARI, Giorgio (2013). Las vidas de los más excelentes arquitectos, pintores y escultores italianos desde Cimabue a nuestros tiempos. Cátedra: Madrid.

ZOPPI, Mariella y DONATI, Cristina (1997). Guida ai Chiostri e Cortili di Firenze. Alinea Editrice: Florencia. 